Note

\title{
Effects of Abasic Site and 8oxoG Lesions on DNA Molecule
}

\author{
Mariko HiguCHI, ${ }^{* 1}$ Miroslav PINAK $* 2$ and Kimiaki SAITO*1
}

KEY WORDS: cluster damaged DNA, molecular dynamics simulation, 8oxoG, AP site, bending structure.

\section{INTRODUCTION}

Ionizing radiation leads to many types of damaged DNA. The damaged DNA having two or more single lesions induced within $10-20$ base pairs (bp), or within 1-2 turns of the DNA helix, is named cluster damaged DNA. Each single lesion is chemically indistinguishable from the one which may be produced endogenously by metabolic processes of organism. It has been observed that cluster damaged DNA is repaired with lesser efficiency than DNA with single lesions. 1,2) Since detail mechanism of repair of cluster damage is not yet fully understood, the reason of retardant of repairing cluster damage is not understood too.

The efficiency of repair enzyme was studied using oligonucleotides with two types of DNA lesions - 7,8-dihydro-8oxoguanine (8oxoG) and apurinic/apyrimidinic (AP). A multiple damage containing $80 x o G$ and AP site is one example of the cluster damage that is difficult to repair. The experimental results showed that the excision of the 8-oxoG lesion by formamidopyrimidine-DNA glycosylase (MutM) is strongly inhibited by the presence of the AP site on the opposite strand with a $1 \mathrm{bp}$ separation from the 8 -oxoG lesion, and inhibited frequency decreases with increasing spacing of the AP site from the 8-oxoG lesion site.

In order to understand to reasons behind the decreased activity of repair enzyme, ${ }^{3)}$ the recognition mechanism of repair enzyme MutM was studied. This research shall serve to help to clarify the mechanism of repair of cluster lesions by MutM repair enzyme focusing on recognition of damage on DNA. The computational approach, molecular dynamics (MD) simulation, has been applied to study cluster damaged DNA segment including AP site and 8oxoG. In this paper there are reported observed differences in structural configuration and electrostatic interaction at the lesion site between single damaged region and cluster damaged region.

\footnotetext{
*1 Radiation Effect Analysis Group, Division of Environment and Radiation Sciences, Nuclear Science and Engineering Directorate, Japan Atomic Energy Agency; 2-4 Shirane, Shirakata-aza, Tokaimura, Naka-gun, Ibaraki 319-1195, Japan.

*2 currently on dispatch to the OECD/NEA Paris, France.
}

\section{METHOD}

\subsection{Model of damaged DNA}

As the model the B-DNA segments of 40 base pair were used and base sequence was same as the polynucleotides used in experiment reported in the paper of O'Neill et al. ${ }^{3)}$ The base initial structure of model DNA was build by NUCGEN module of AMBER 8.0 software package. ${ }^{4)}$ In the case of damaged DNA, the regular residues were replaced by lesion residue. Simulated molecules were: two cluster damaged DNA molecules, three single damaged DNA molecules and native (non-damaged) DNA molecule as a reference simulation. Each damaged DNA included two lesion residues; AP site and 8oxoG located on opposite strands and separated by 1 base pair. Two cluster damaged DNA were denoted as [-1] and $[+1]$, (the number ' 1 ' in brackets refers to the number of base pairs separating the AP site from $80 x 0 \mathrm{G}$ on the complementary strand and the symbols ' + ' and ' - ' indicate the direction of separation from $80 x \mathrm{oG}$ ). The position of 8-oxoG was identical in each of 2 models of cluster damaged DNA, (Fig. 1). Three single damaged DNA were denoted as AP $[-1]$ and AP $[+1]$. Damaged DNA AP $[-1]$ and AP $[+1]$ included one AP site which located the same position of the AP site in cluster damaged DNA $[-1]$ and $[+1]$, respectively. The single 8oxoG damaged DNA contained 8oxoG which was located at the same position as the $80 x 0 \mathrm{G}$ on the cluster damaged DNA.

\subsection{Decided missing force field parameters of damaged} residue

The $a b$ initio calculation of lesion residue using Gaussian035) was performed in order to obtain missing force field parameters required for molecular dynamics simulation. The 6$31 \mathrm{G}(\mathrm{d})$ basis set and the Hatree-Fock method were used. All three residues - damaged residue and its respective opposite side residues, were calculated in one set. During ab initio calculation, the structure of pentose of side nucleotide residues was restricted as to be the same as in the B-DNA. The following combinations were calculated: Adenine-8oxoG-Adenine, Cytosine-AP site-Cytosine and Cytosine-AP site-Guanine. Point charges were obtained using RESP module of AMBER 8.0 software package. In the result of calculation, the structure of damaged residues was nearly the same as that of normal (i.e. non-damaged) residue except for positions of modified 


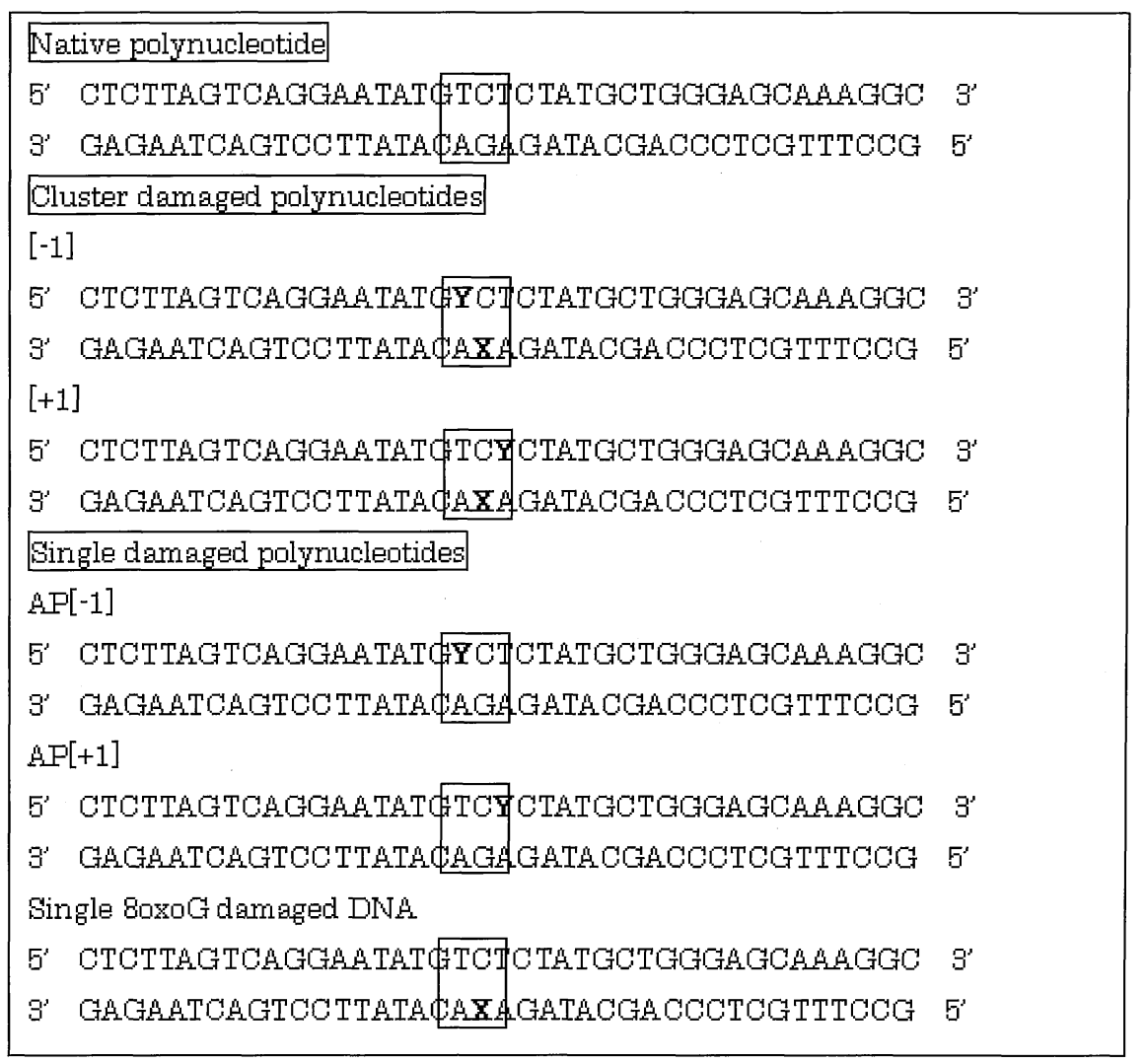

Fig. 1 The 40 base pair sequences of the model polynucleotides. In cluster damaged polynucleotide, [X] indicates 8oxoG, and AP site is denoted as $[Y]$. The $[-1]$ and the $[+1]$ show the number of base pairs separating the AP site from the 8oxo-G on the complementary strand. Damaged regions are shown in boxes.

atoms. Contrary, the point charges of $80 x 0 \mathrm{G}$ atoms were different from those of Guanine at most atoms (not only modified atoms), (Fig. 2). The point charges of AP site were different from pentose of cytosine in AMBER force field. The point charges of AP site in C-AP-C was slightly different from it of AP site in C-AP-G.

\subsection{Protocol of Molecular dynamics simulation}

Molecular dynamics simulation of damaged DNA was carried out using Sander module of AMBER 8.0. Model DNA molecule was located in explicit water box and the simulations were performed using periodic boundary conditions. To neutralize negative charges of DNA molecule, several sodium ions were placed in appropriate positions which were calculated using LEaP module of AMBER 8.0. In order to adjust positions of water molecules around DNA and counter-ions, the potential energy minimization was carried out. DNA and counter-ions were fixed during first 5,000 steps and it was permitted to move water molecules only. Next, 15,000 steps of potential energy minimization for all molecules were carried out. After energy minimization, MD simulation was performed in order to equilibrate the system at $300 \mathrm{~K}$ and $1 \mathrm{bar}$. For equilibration, temperature of the system increased stepwise from $0 \mathrm{~K}$ to $300 \mathrm{~K}$ during $100 \mathrm{ps}$. After next $100 \mathrm{ps}$ of MD simulation at the constant temperature, the system stabi- lized at $300 \mathrm{~K}$. To equilibrate density of the system, the $200 \mathrm{ps}$ of MD simulation at the constant pressure was carried out and the density of the system became equilibrated at about $1.02 \mathrm{~g} / \mathrm{cm}^{3}$. After equilibration, $2 \mathrm{~ns}$ of production MD simulation was performed under constant energy and constant volume conditions.

\section{RESULTS}

\subsection{Structural equilibration of model DNA molecules}

In order to confirm that the structure of the model DNA molecule equilibrated, the root mean square deviation (RMSD) of DNA molecules for $2 \mathrm{~ns}$ was calculated, (Fig. 3). The RMSD value represents the average deviation from initial structure of MD simulation calculated for heavy atoms of main chain of DNA molecule. The RMSD values of each molecule increased rapidly during the first $0.4 \mathrm{~ns}$ and then increased slightly up to $1 \mathrm{~ns}$. After 1ns, the RMSD values were relatively stable, and structures of each DNA molecules were considered to be equilibrated. The data of equilibrated structures between 1 and $2 \mathrm{~ns}$ were used for the following analysis.

It has been observed that the structure of the cluster damaged DNA [+1] was the most structurally changed molecule among model DNA molecules in $2 \mathrm{~ns}$ MD simulation. Its RMSD value was stable around at $11 \AA$ (Angstrom $-10^{-10} \mathrm{~m}$ ), 
a)

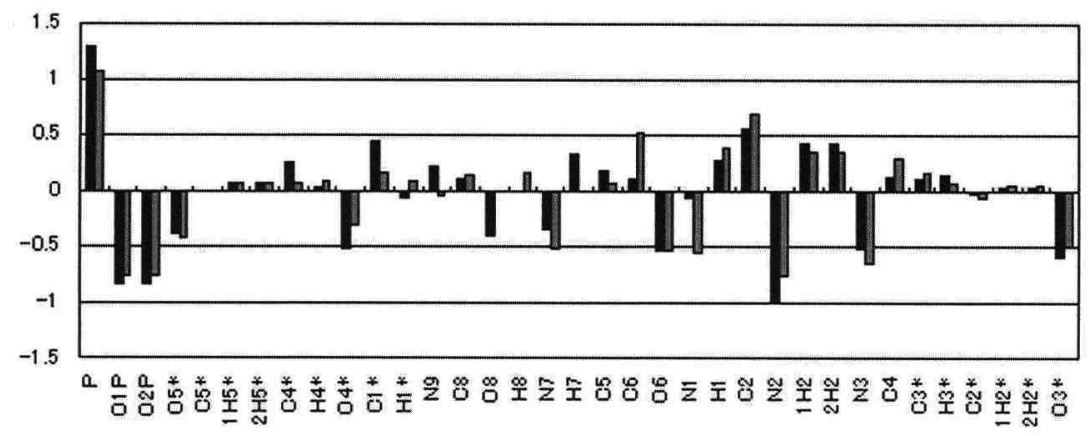

b)

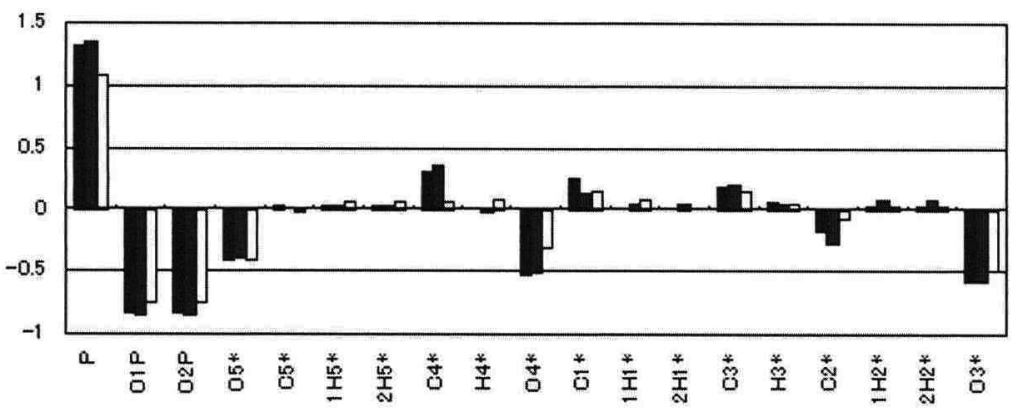

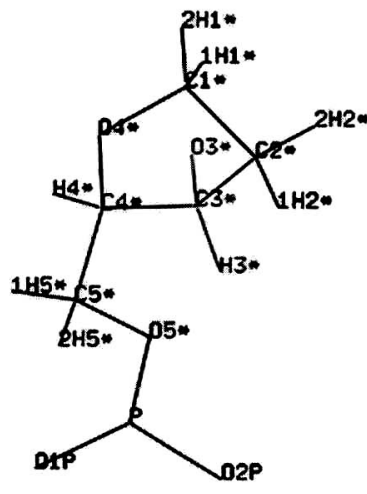

AP site

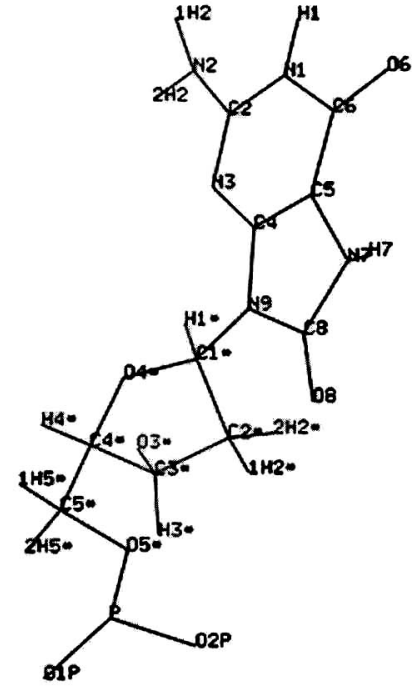

8oxoG

Fig. 2 The point charges of lesion residues, which are the results of the $a b$ initio calculation. The graph a) shows the atomic point charges of $80 x 0 \mathrm{G}$ (black) and that of the guanine (gray) which are included in AMBER force field parameters. The graph b) shows the atomic point charges of AP site in G-AP-C (black), AP site in C-AP-C (gray) and the pentose of cytosine (white) included in AMBER force field parameter. The structure of AP site and 8oxoG are also shown. The vertical axis shows the atomic point charge and the horizontal one atom types (AMBER nomenclature).

higher than that of other damaged as well native DNA, which were stable at around $8 \AA$. The RMSD value of cluster damaged DNA [ -1$]$ fluctuated between $7 \AA$ and $10 \AA$. The longer calculation seems to be needed in order to achieve stable configuration enabling statistically justified analysis.

In order to evaluate time dependence of structural changes at the lesion site, the RMSD for damaged residue and its complementary residue were also calculated, (not shown) The RMSD values of $[+1]$ model were different from those of the initial state and were stable in $1-2 \mathrm{~ns}$. It indicated that the structure of lesion site was stable during $1 \mathrm{~ns}$ of production MD simulation. 


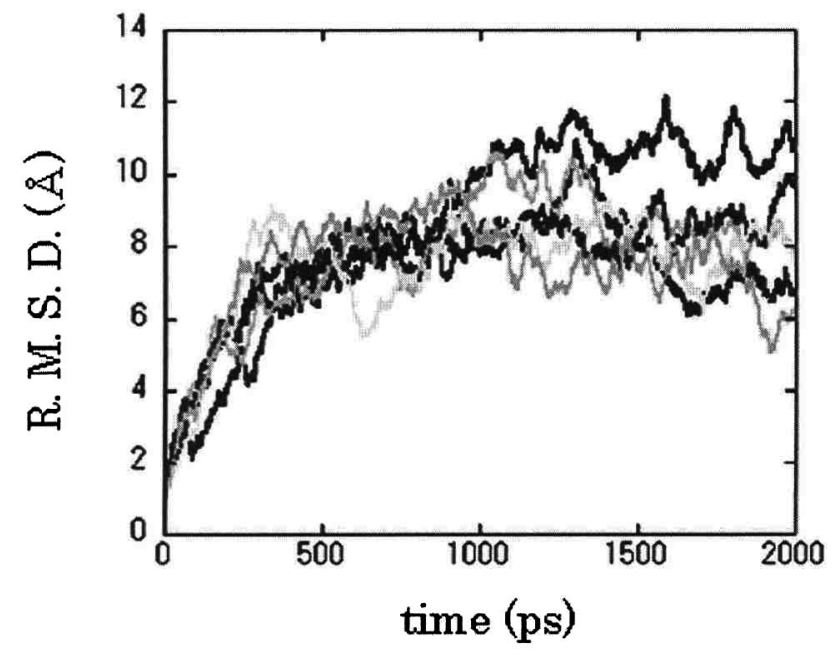

Fig. 3 The RMSD of heavy atoms of main chain of DNA molecule during production MD simulation. The RMSD values of each molecule increased rapidly during the first $0.4 \mathrm{~ns}$. After $0.4 \mathrm{~ns}$ and up to $1 \mathrm{~ns}$, most RMSD values increased slightly. Most RMSD values were equilibrated after $1 \mathrm{~ns}$. Red line, blue line, green line, pink line, yellow line and pale blue line graph show cluster damaged DNA $[-1]$, cluster damaged DNA [+1], AP site damaged DNA AP $[-1]$, AP site damaged DNA AP $[+1], 80 x 0$ G damaged DNA and native DNA, respectively.

\subsection{Electrostatic energy interaction between lesion site and its complementary site}

The electrostatic interaction energy between lesion residue and its complementary residue was calculated, (Fig. 4). The electrostatic interaction energy between the AP site and its complementary site was more repulsive than the interaction energy of non-damaged residue pair. The electrostatic interaction energy of normal G-C pair as well the one of damaged 8oxoG-C pair of cluster damaged DNA [ -1$]$ were attractive, however in cluster damaged DNA [+1] it was not attractive. The difference of electrostatic interaction energy between normal G-C pair and 8oxoG-C pair (about $0 \sim 3 \mathrm{kcal} / \mathrm{mol}$ ) was lesser than the difference of electrostatic interaction energy between normal pair and the base pair including AP site (about $9 \sim 16 \mathrm{kcal} / \mathrm{mol}$ ). Along with this result, the observed effect of changing normal residue to AP site was also larger than the one of changing normal $\mathrm{G}$ to $80 x 0 \mathrm{G}$ in cluster damaged DNA. This result may imply that the electrostatic energy is significant factor driving the impact of damage.

\subsection{Bending structure of single damaged DNA}

In order to describe details of structural changes of the damaged structure of DNA, two base pair parameters (tilt and roll) were measured. These base pair parameters enable to describe relative position between two base pairs while base pair is assumed as rigid body. Roll, tilt, and twist angle define the rotational deformation. Roll is defined as the rotation along the long axis of the base pair plane and describes DNA groove bending; a positive roll angle indicates that a base pair

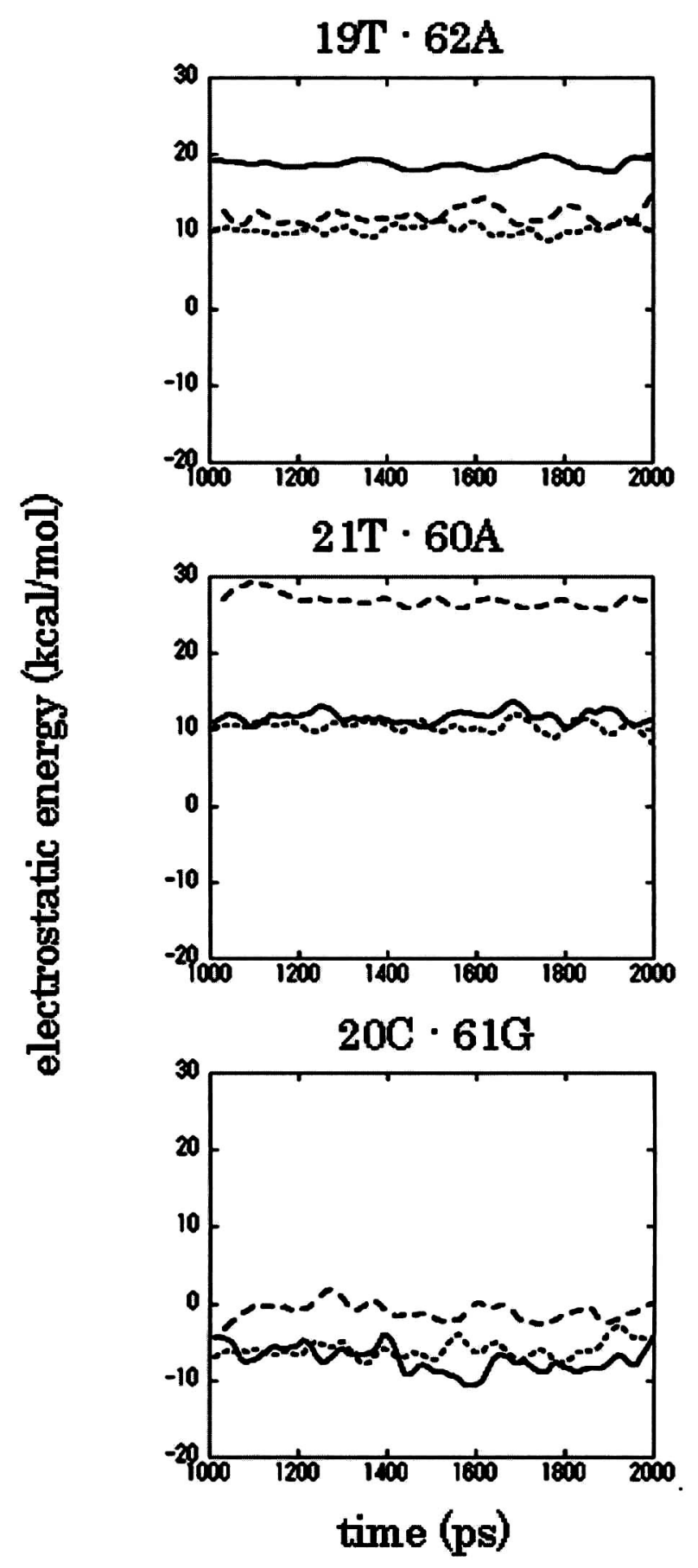

Fig. 4 The electrostatic interaction energy between damaged residue and its complementary residue pair. Full line, dashed line and dotted line graphs show cluster damaged $\mathrm{DNA}[-1]$, cluster damaged $\mathrm{DNA}[+1]$ and native DNA, respectively. The electrostatic interaction energy between AP site and its complementary residue is higher than that of non-damaged residue pair.

step opens up toward the minor groove, while a negative roll angle indicates that a base pair step opens up toward the major groove. Tilt is the rotation defined with respect to the short axis of the base pair plane. A positive tilt angle indicates that 
the base pair step opens on the side of the sequence strand. Twist is the helical rotation between successive base pairs. ${ }^{6}$ ) The average values of each base pair parameters of every two next base pairs in single damaged DNA were calculated, (Fig. 5). It was found that the average tilt values of base pairs including AP site were smaller than that of other base pairs. The average tilt values of the base pairs including AP site in AP $[+1]$ were -17.8 degrees and that of the base pairs including AP site in AP $[-1]$ were -3.6 degrees, while the average tilt values of normal base pairs were around 0 degree. The average tilt values of normal base pairs were between -3 degree and 3 degree. In our case, the negative tilt values of base pairs including AP site imply that the DNA is bent toward the direction of AP site. The average tilt value of base pairs including $80 x 0 \mathrm{G}$ was 2 degrees and it was not different from that of other non-damaged base pairs. As for the roll value there was not observed large difference between damaged base pairs and non-damaged base pairs. The most roll values of normal base pairs were between -2 degree and 10 degree. The average roll values of base pairs including AP site slightly tend to increase (9.7 degree in AP $[-1]$ and 12.1 degree in $\mathrm{AP}[+1])$ if compared with those of normal base pairs. In this case, the bending direction was causing pressing and narrowing major groove.

According to the results of X-ray crystallography the MutM was in contact with five base pairs of DNA in 8oxoG damaged DNA-MutM complex structure. ${ }^{7)}$ In order to investigate the structure of whole of cluster damaged DNA in relation to MutM size, the structure of the five base pairs of lesioned DNA was measured. Net tilt $\theta_{T}$ and net roll $\theta_{R}$ of five base pairs were used. Net tilt and net roll are calculated by considering the cumulative projection of tilt and roll at each two base pair step, and are adjusted for twist into the plane of a reference base pair. ${ }^{6)}$ The reference base pair was set as the one located at the end of measured five base DNA segment. The bend direction was described using the value of net tilt and net roll. Net tilt and net roll indicate that difference between their values at each end of respective damaged region do not affect the value of twist. Net tilt and net roll angle depend on end-to-end distance. Further, the bending magnitude, derived from net tilt and net roll, $+\sqrt{\theta_{T}^{2}+\theta_{R}^{2}}$ was calculated. Figure 6 shows the net tilt and net roll angle of single damaged DNA with AP site of $\mathrm{AP}[-1]$ shift minus 1 base pair from the center of five residues, and AP site of $\mathrm{AP}[+1]$ shift plus lbase pair from the center of five residues. Table 1 shows the average and deviation of net tilt, net roll, net twist and bending magnitude. In both AP sites, AP $[-1]$ as well AP $[+1]$, net tilt and net roll were positive. Bend magnitudes were different between those of AP [ +1] (28.4 degree) and AP [ - 1] (17.0 degree). It implies that the bending magnitude of AP site region depends on the base sequence. In $80 x$ oG damaged DNA, the tilt value was positive and the roll value was negative. This tendency was similar to that of native DNA. Bending magnitude of 8oxoG region (18.5 degrees) was smaller than that of AP site regions, but was larger than that of native DNA. Naturally, if location of lesion site among base pair DNA is changed, bending direction of the five base pair DNA is changed too. Table 2 shows averages and deviations of net angles of lesion DNA included those for the lesion in center of five residues. The bending directions of both AP site in $\mathrm{AP}[-1]$ and AP $[+1]$ were more similar to each other than to that of five residues in which AP site was not in the same position.

\subsection{Bending structure of cluster damaged DNA}

The average values of each base pair parameters of every two next base pairs in cluster damaged DNA were calculated, (Fig. 7). It was found that the average tilt value of base pairs
Tilt

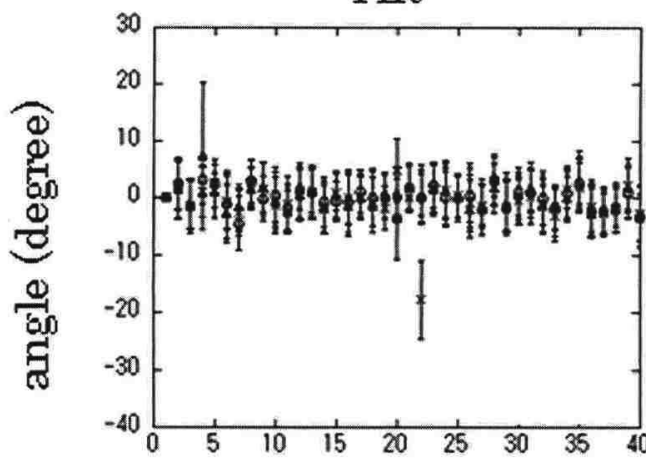

Roll

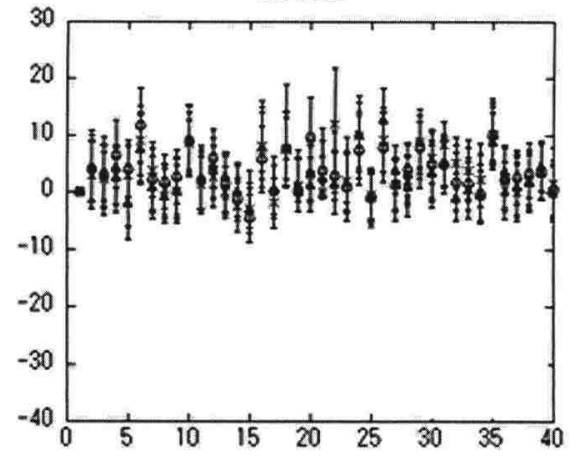

\section{the number of base pair (bp)}

Fig. 5 The tilt and roll angle between base pair and its next base pair of single damaged DNA. Each point indicates average tilt or roll value during lns simulation for each two next base pairs, and error bar shows its deviation. $\bigcirc, \times, \Delta$ and $\boldsymbol{\Delta}$ graphs indicate single AP site damaged DNA AP $[-1], \mathrm{AP}[+1]$, single $80 x 0 \mathrm{G}$ damaged DNA, and native DNA, respectively. The average value of tilt angle of the base pair with AP site is smaller than others. It shows that DNA deformed and was pressing the AP site region. The deviation of tilt angle of near end of native DNA is larger than others. The average values of roll angle were similar if compared between damaged DNA and native DNA. 
Table 1 The average values and deviation angles of net tilt, net roll, net twist and bend magnitudes of single damaged DNA, with AP site shift minus 1 base pair from middle in AP [-1] and shift plus 1 base pair from middle in AP [ +1$]$.

\begin{tabular}{|l|c|c|c|c|c|c|c|c|}
\hline \multirow{2}{*}{} & \multicolumn{2}{|c|}{ Net tilt } & \multicolumn{2}{c|}{ Net roll } & \multicolumn{2}{c|}{ Net twist } & \multicolumn{2}{c|}{ Bend magnitude } \\
\cline { 2 - 9 } & average & deviation & average & deviation & average & deviation & average & Deviation \\
\hline $\mathrm{AP}[-1]$ & 13.3 & 9.5 & 4.1 & 8.4 & 126.1 & 8.2 & 17.0 & 8.1 \\
\hline $\mathrm{AP}[+1]$ & 24.6 & 8.7 & 6.2 & 12.4 & 127.4 & 7.0 & 28.4 & 8.1 \\
\hline 80xoG & 15.8 & 9.8 & -3.4 & 7.8 & 124.3 & 7.1 & 18.5 & 8.8 \\
\hline
\end{tabular}

Table 2 The average and deviation angle of net tilt, net roll, net twist and bend magnitude of single damaged DNA. The lesion site is located in the center of five base pairs.

\begin{tabular}{|l|c|c|c|c|c|c|c|c|}
\hline & \multicolumn{2}{|c|}{ Net tilt } & \multicolumn{2}{c|}{ Net roll } & \multicolumn{2}{c|}{ Net twist } & \multicolumn{2}{c|}{ Bend magnitude } \\
\cline { 2 - 10 } & average & deviation & average & deviation & average & deviation & average & Deviation \\
\hline $\mathrm{AP}[-1]$ & 15.9 & 10.0 & 6.4 & 11.4 & 120.0 & 8.7 & 21.2 & 8.7 \\
\hline $\mathrm{AP}[+1]$ & 20.3 & 12.8 & 13.7 & 10.4 & 129.6 & 6.6 & 27.6 & 10.4 \\
\hline 80xoG & 15.8 & 9.8 & -3.4 & 7.8 & 124.3 & 7.1 & 18.5 & 8.8 \\
\hline
\end{tabular}

including AP site was smaller than that of other base pairs. The average tilt values of normal base pairs were located between -3 and 3 degrees. The average tilt value of base pairs including AP site of cluster [+1] was -23.4 degrees, and that of cluster [ -1$]$ was -10.3 degree. In the case of $[+1]$, the base pairs included both AP site and 8 oxoG. In case of $[-1]$, these base pairs included AP site but not 8 oxoG. The absolute

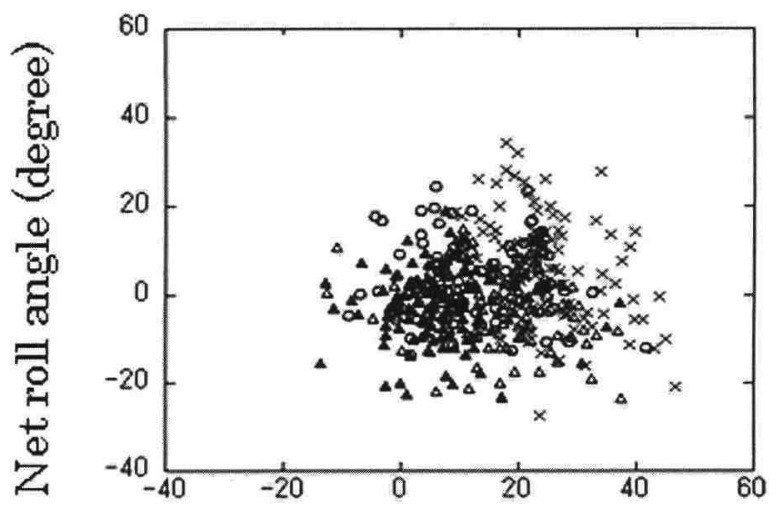

\section{Net tilt angle (degree)}

Fig. 6 The net tilt and net roll angle of single damaged DNA with AP site of AP $[-1]$ shift minus 1 base pair from the center of five residues, and $\mathrm{AP}$ site of $\mathrm{AP}[+1]$ shift plus 1 base pair from the center of five residues. The sequence of five residues without $80 x 0 \mathrm{G}$ was same as each cluster damaged lesion case. $O, \times, \Delta$ and $\boldsymbol{\Delta}$ graph indicated single AP site damaged DNA AP $[-1]$, single AP site damaged DNA AP [+1], single 80xoG damaged DNA, and native DNA, respectively. The distribution of both AP sites shifted to positive net tilt and positive net roll angle. The distribution of $80 x 0 \mathrm{G}$ is not much different from that of the native guanine. tilt value of AP site in cluster damaged DNA was larger than that in single damaged DNA. The absolute tilt value of AP site in [+1] was larger than that in $[-1]$ in the case of single AP site damaged DNA molecules. In the base pairs including $80 x 0 \mathrm{G}$ in $[-1]$, the tilt value (1.2 degree) was not different from those of non-damaged base pairs. The most roll values of normal base pairs were located between -2 and 10 degrees. The roll value of the base pairs including lesion site of cluster damaged DNA was not very different from that of non-damaged base pairs, but the average roll values of base pairs including AP site slightly changed toward positive values ( 8.2 degree in $[-1]$ and 11.2 degree in $[+1])$. These changes were similar to those observed in single AP site damaged DNA.

In addition, the net tilt and net roll of five residues which included 8 oxoG damaged residue located in the middle of five residues with AP site, were calculated (Fig. 8). Bending direction of cluster damaged DNA was more similar to that of AP site single damaged DNA than to that of single 8 oxoG damaged DNA. The bending magnitude of cluster damaged DNA was similar to that of each single AP site damaged DNA.

The deviations of bend magnitudes of cluster damaged DNA were 9.1 degree in $[-1]$ and 8.9 degree in $[+1]$. The deviation of bend magnitudes of native DNA was 7.4 degree (Table 3). This indicates that the bending distribution of cluster damaged DNA was slightly wider than that of native DNA. However the differences were not significant. The broad bending distribution indicates that the flexibility of DNA is large. It is assumed that the flexibility of cluster damaged DNA with AP site and $80 x 0 G$ slightly decreases from that of native DNA.

\section{CONCLUSION}

In this study, several effects of damage on the DNA structure were observed. In the case of single lesion, the DNA was bent at the base pairs, including pressing AP site toward the neighboring base and narrowing the AP site region. The 
Tilt

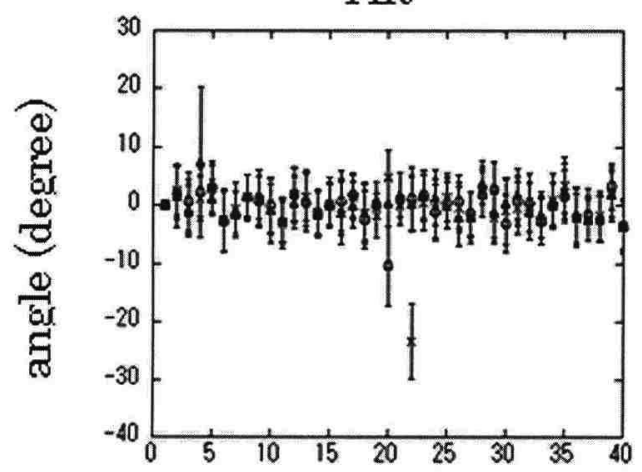

Roll

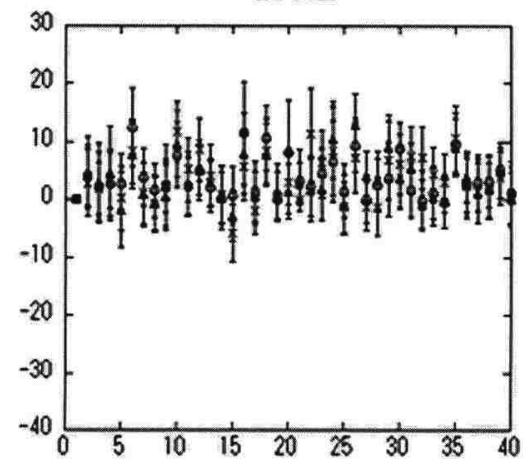

\section{the number of base pair (bp)}

Fig. 7 These graphs show tilt and roll angles between base pair and its next base pair of cluster damaged DNA. Each point indicates average tilt or roll value during 1 ns simulation for each two base pairs, and error bar shows its standard deviation. $\bigcirc, \times$ and $\Delta$ graphs indicate cluster damaged DNA [-1], cluster damaged DNA [+1] and native DNA, respectively. The average values of tilt angle of the base pair with AP site are smaller than others. The average values of roll angle were similar for both, damaged and native DNA.

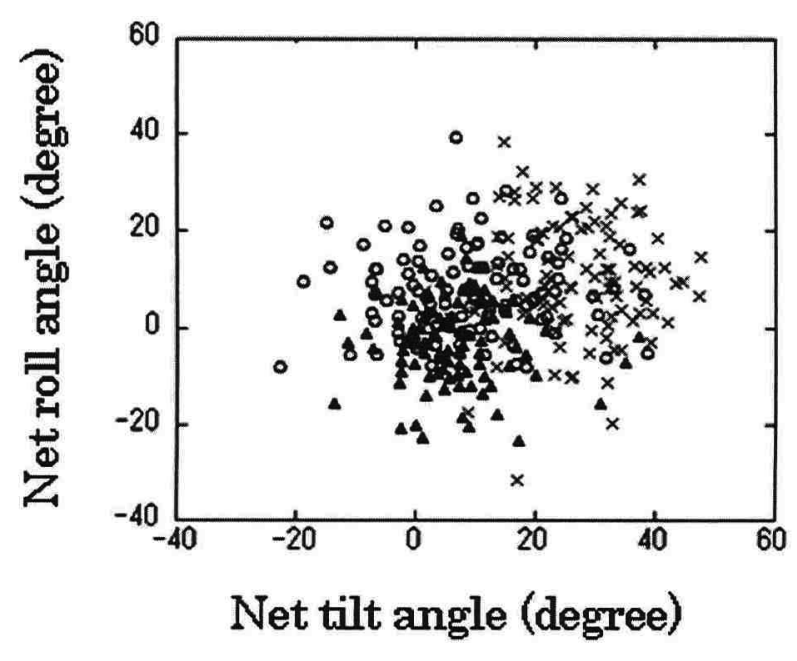

Fig. 8 The net tilt and the net roll angle of five five base pairs. The base pair with $80 x 0 \mathrm{G}$ is located in the middle of five base pairs. $\bigcirc, \times$ and $\boldsymbol{\Delta}$ graphs indicate cluster damaged DNA [-1], cluster damaged DNA [+1] and native DNA, respectively. lesioned DNA slightly bent at the base pair with $80 x 0 \mathrm{G}$ however, the bending magnitude was smaller than that of AP site. It implies that the effect of AP site is bigger than that of $80 x 0$ G in single lesioned DNA. Similar tendency was observed also in cluster damaged DNA. The cluster damaged DNA was bent mainly at AP site. The total bending direction and magnitude of cluster lesion residues were more similar to that of single AP site than to bending of single $80 x 0 \mathrm{G}$. The effect of 8 oxoG on cluster damaged DNA structure was smaller than that of AP site. In electrostatic interaction, effect of the changing normal residue to AP site was bigger than that of changing normal $G$ to $80 x 0 G$ in cluster lesions DNA. The structure of cluster damaged DNA was different from that of single 8oxoG damaged DNA. This situation may affect recognition of lesion and its repair, suggesting that cluster lesion has lesser probability of being recognized and repaired. These results are intended to serve for the future research on the enzymatic recognition of cluster damaged DNA.

\section{ACKNOWLEDGMENT}

This study was financially supported by the Budget for Nuclear Research of the Ministry of Education, Culture, Sports, Science and Technology, based on the screening and counseling by the Atomic Energy Commission.

Table 3 The average and deviation angle of net tilt, net roll, net twist and bend magnitude of cluster damaged DNA.

\begin{tabular}{|c|c|c|c|c|c|c|c|c|}
\hline & \multicolumn{2}{|c|}{ Net tilt } & \multicolumn{2}{c|}{ Net roll } & \multicolumn{2}{c|}{ Net twist } & \multicolumn{2}{c|}{ Bend magnitude } \\
\hline & average & deviation & average & deviation & average & deviation & average & Deviation \\
\hline$[-1]$ & 8.9 & 12.4 & 8.3 & 9.1 & 134.3 & 7.2 & 17.4 & 9.1 \\
\hline$[+1]$ & 26.8 & 9.3 & 10.1 & 12.2 & 127.8 & 6.8 & 31.3 & 8.9 \\
\hline Native & 6.1 & 8.5 & -2.9 & 8.4 & 134.5 & 7.0 & 11.6 & 7.4 \\
\hline
\end{tabular}




\section{REFERENCES}

1) L. Harrison, Z. Hatahet and S. S. Wallace; J. Mol. Biol., 290, 667-684 (1999).

2) M. David-Cordonnier, J. Laval and P. O'Neill; J. Biol. Chem., 275, 11865-11873 (2000).

3) C. G. Pearson, N. Shikazono, J. Thacker and P. O'NeILL; Nucl. Acids Res., 32, 263-270 (2004).

4) D. A. Case, T. A. Darden, T. E. Cheatham, III, C. L. Simmerling, J. Wang, R. E. DuKe, R. Luo, K. M. MERZ, B. Wang, D. A. Pearlman, M. Crowley, S. Brozell, V. Tsui, H. Gohlke, J. Mongan, V. Hornak, G. Cui, P. Beroza, C. Schafmeister, J. W. Caldwell, W. S. Ross and P. A. Kollman; AMBER8 (2004), University of California, San Francisco.

5) M. J. Frisch, G. W. Trucks, H. B. Schlegel, G. E. Scuseria, M. A. Robb, J. R. Cheeseman, J. A. Montgomery, Jr., T. VReven, K. N. Kudin, J. C. Burant, J. M. Millam, S. S. Iyengar, J. Tomasi, V. Barone, B. Mennucci, M. Cossi, G. Scalmani, N. Rega, G. A. Petersson, H. Nakatsuji, M. Hada, M. Ehara, K. Toyota, R. Fukuda, J. Hasegawa, M. Ishida, T. NaKaJima, Y. Honda, O. KitAo, H. NAKaI, M. Klene, X. Li, J. E. Knox, H. P. Hratchian, J. B. Cross, C. Adamo, J. Jaramillo, R. Gomperts, R. E. Stratmann, O. YazyeV, A. J. Austin, R. Cammi, C. Pomelli, J. W. Ochterski, P. Y. Ayala, K. Morokuma, G. A. Voth, P. Salvador, J. J. Dannenberg, V. G. Zakrzewski, S. DAPPrich, A. D.
Daniels, M. C. Strain, O. Farkas, D. K. Malick, A. D. Rabuck, K. Ranghavachari, J. B. Foresman, J. V. Ortiz, Q. Cul, A. G. Baboul, S. Clifford, J. Cioslowski, B. B. Stefanov, G. Liu, A. Liashenko, P. Piskorz, I. Komaromi, R. L. Martin, D. J. Fox, T. Keith, M. A. Al-Laham, C. Y. Peng, A. Nanayakkara, M. Challacombe, P. M. W. Gill, B. Johnson, W. Chen, M. W. Wong, C Gonzalez, and J. A. Pople; Gauusian 03, Revision C.02, Gaussian, Inc., Wallingford CT, 2004.

6) T. SCHILICK; "Molecular Modeling and Simulatior," p.135141, 153-158 (2002), Springer-Verlag New York Inc., New York.

7) J. C. Fromme and G. L. Verdine; J. Biol. Chem., 278, $51543-51548$ (2003).

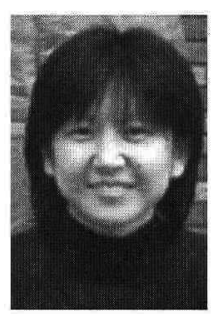

樋口 真理子（ひぐち まりこ）

日本原子力研究開発機構放射線影響解析 研究グループ技術開発協力員。九州大学 大学院理学研究科博士課程終了後, 原子 力研究所博士研究員を経て現職。

専門分野：生体分子の計算機シミュレー ション

E-mail: higuchi.mariko@jaea.go.jp 
Jpn. J. Health Phys., 42 (2) 174- 175 (2007)

\section{Current Topics}

\section{Participating AOCRP-2 in Beijing, China}

\begin{abstract}
$\mathrm{Hao} \mathrm{Hu}^{* 1}$

\section{Organization and Purpose of the Congress}

I attended to the Second Asian and Oceanic Congress for Radiological Protection (AOCRP-2) held in Beijing of China from Oct. 9 to 13 2006. The congress is hosted by Chinese Society of Radiation Protection (CSRP), Chinese Nuclear Society (CNS), Chinese Environmental Society (CES), Chinese Medical Association (CMA), China Preventive Medicine Association (CPMA), China Isotope \& Radiation Association (CIRA), and under full support of Chinese Government, the International Radiation Protection Association (IRPA) and Asian and Oceanic Association for Radiation Protection (AOCRP), and sponsored by Japan Health Physics Society (JHPS) etc. About 26 countries' researchers and officials attended the congress. The congress not only provides a communication place to solve the problem of Asia regionally, but also impacts on the radiation protection in the world.
\end{abstract}

\section{Congress Contents}

In the opening session, the chairman of the conference Mr. Pan ZIQIANG, ICRP chairperson Mr. Holm, AOARP chairman Mr. NAKAMURA stated, with the changing risk, radiation protection is performing a very important role. Researchers all over the world need to communicate deeply, and cooperate to solve problems. This conference provided an opportunity for researchers and managers to communicate, and promoted the development of radiation protection. Figure 1 shows the hall held opening session.

Dr. HoLM, the chairman of ICRP made a presentation on the new recommendation. Most recommendations will remain because they work, and they are clear enough. Some parts need to be explained and added, because more guidance is needed and somewhere has been a void.

On the following day of the opening session, technical sessions of oral presentations started using 3 separate rooms. In each session, two session coordinators controlled the progress of the session.

The congress dealt with 15 topics;

( 1 ) Ionizing Radiation Protection Principles

(2) Radiation Protection Standards and Regulations

( 3 ) Monitoring Methods and Equipment

(4) Radiation Dosimetry

*1 Department of Nuclear Engineering and Management School of Engineering, The University of Tokyo; $2-11-16$, Yayoi Bunkyo-ku, Tokyo 113-0032, Japan.

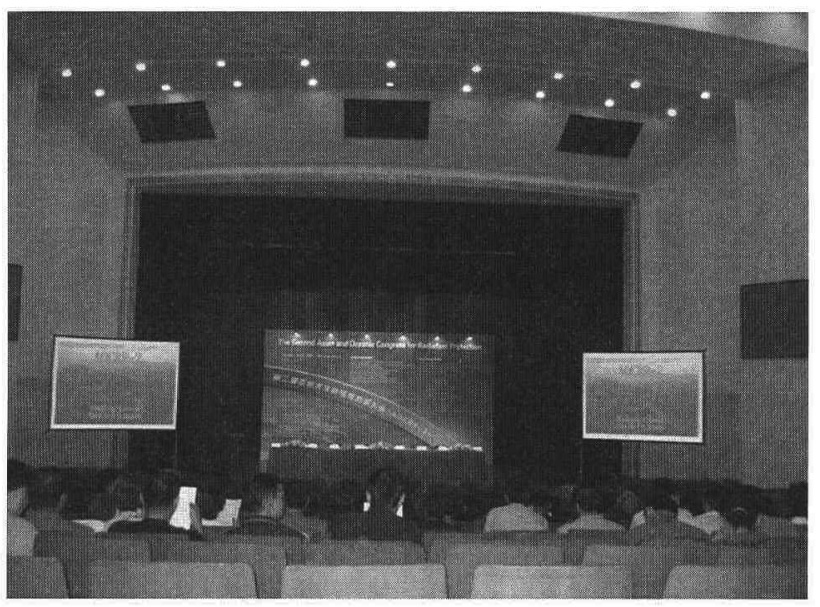

Fig. 1 The Hall held opening session of AOCRP-2.

( 5 ) Environmental Monitoring and Assessment

(6) Radiation and Nuclear Safety

( 7 ) Radioactive Waste management and Radioactive Material Transportation

( 8 ) Nuclear Installation Decommissioning and Decontamination

(9) Safety and Security of Radiation Sources

(10) Nuclear and Radiological Emergency Preparedness

(11) Radiation Biological Effects

(12) Radiological Epidemiology

(13) Radiological Medicine

(14) Comments on New Recommendation of CIRP and BSS Discussion

(15) Report from Each Society and IRPA Associate Societies Forum

Previous to the technical session of the day, refresher courses were programmed. On one of the Refresher Courses, Mr. $\mathrm{K}$. MRABIT made a presentation about international radiation safety standards and their application. He made a explanation of IAEA technology program from 1994. The program is every country's infrastructures of radiation protection should accommodate to the international standard made by IAEA. Until now, there are 30 African countries, 25 Asian countries, 22 European countries, and 15 American countries joined the program. The program provides the communication opportunities actively and provides the application samples to the counties which joined the program.

Poster presentations were organized in last two days using two separate rooms which had been used for oral presentation. Further, the time and duration for putting up the posters was appointed by organizer because the space for putting up the posters were very limited. Since the posters were not categorized in the session rooms, it was difficult to find the poster presentation according to the program or the book of abstract. However, author and audience were actively discussed here and there. Figure 2 shows the situation of poster session.

At last we had a technical tour arranged by the congress to China Institution of Atomic Energy (CIAE). CIAE was found- 